\title{
4D BIM Integrated Construction Supply Chain Logistics to Optimise On-Site Production
}

\author{
${ }^{\text {a }}$ Leslie J. Magill; ${ }^{\mathrm{b}}$ Naeimeh Jafarifar; ${ }^{\mathrm{c}}$ Alan Watson; ${ }^{\mathrm{d}}$ Temitope Omotayo \\ a Mace International, UAE, Email: Imagill6@gmail.com \\ b, c, d Aberdeen's Robert Gordon University, School of Architecture and built Environment, \\ Email: n.jafarifar@rgu.ac.uk; a.watson@rgu.ac.uk; t.s.omotayo@rgu.ac.uk
}

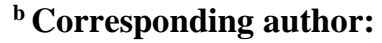 \\ Naeimeh Jafarifar \\ The Scott Sutherland School of Architecture and Built Environment, Robert Gordon University, Sir Ian \\ Wood Building, Riverside East, Garthdee Road, ABERDEEN AB10 7GJ, UK \\ Tel.: +44 (0) 1224 263523, \\ Email: n.jafarifar@rgu.ac.uk
}

\begin{abstract}
Loss of productivity through on-site delays and disruptions is a significant problem in the construction industry. This can be caused by workforce, materials, and equipment clashes. A major need for the industry is to improve construction logistic efficiencies for materials and equipment from manufacture to the point of use by the workforce. The authors investigate the effectiveness and efficiency of integrated construction supply chain logistics (ICSCL) using 4D Building Information Models (BIM), via three information streams: literature, a case study of the Elephant and Castle project $(\mathrm{E} \& \mathrm{C})$, and a survey from UK construction professionals. The results illustrate, although BIM of various levels is currently in use throughout the UK, 4D BIM for ICSCL is not extensively utilised due to an absence of strategy, perceived costs of IT, and training requirements. That use could potentially add value with a trusted supply chain and disciplined planning using a multiple stream logistic model.
\end{abstract}

Keywords: 4D BIM; Integrated Construction Supply Chain Logistics; On-Site Production; Time predictability.

\section{Introduction}

The UK construction industry accounts for $60 \%$ of all materials used, and generates $45 \%$ of all $\mathrm{CO} 2$ emissions in the UK [1]. More than 400 million tonnes of materials are delivered to project sites each year, of which 60 million tonnes are declared as waste due to damage and over ordering [2]. Waste of building materials has even been claimed to be $30 \%$ by National BIM Report [3].

Manufacturers are essential contributors to the overall efficiency of the construction sector by producing $40 \%$, by value, of the UK construction output [4]. The UK Government's strategic vision, Construction 2025, aims to reduce the cost of whole life built assets by 33\%, lower greenhouse gases by 50\% and deliver construction projects from inception to delivery $50 \%$ faster by 2025 [5]. To achieve this, improving construction logistic efficiencies for materials and equipment from manufacture to the point of use by the workforce during the construction phase can be a progressive step. 
Construction products can be brought to an accessible and available site workface pre-planned by 4D BIM with a managed integrated resilient supply chain. 4D BIM is a derivation of the 3D BIM geometry and an optimization of the resources by intelligent linking of attributes in the model to a construction programme or schedule-related information. 4D BIM can visualise the interaction between the integrated construction supply chain logistics (ICSCL) to avoid trade contractor clashes of on-site materials, laydown zones and the workface requirements of plant and equipment. This interaction will raise production levels, thereby realising efficiencies of time and quality assurance while mitigating the environmental impact.

BIM Level 2 is a prerequisite for UK Government projects by 2016 [4]. However, the logistical efficiencies that could be realised by 4D BIM are still in their infancy.

The aim of this study is to increase the current understanding of the issues surrounding 4D BIM when used for ICSCL management to realise construction phase efficiencies, thereby supporting Construction 2025. The problem addressed is how to optimise the ICSCL in the UK, in the present conditions, using 4D BIM. The results will be of benefit to the construction industry by adding value to project planning at the worksite level and when dealing with the critical issues of time certainty, materials waste and production delays.

The inter-related objectives of this research are:

1) Identifying the drivers and barriers that will practically align construction logistic elements to the workface utilising integrated 4D BIM

2) Evaluating logistic models which support the use of 4D BIM within ICSCL

3) Assessing the implementation of $4 \mathrm{D}$ BIM with ICSCL in the current operational projects

4) Formulating recommendations for practical methodologies for construction efficiencies related to project time certainty combined with the environment considerations

\section{Materials and Methods}

Figure 1 illustrates the outline methodology of this research. Firstly, a clear picture of 4D BIM and ICSCL is drawn from the literature. This orientates the structure of empirical studies with the trends and themes of data collected via interviews in a live project site case study setting [6]. The result is enriched by outlining the views of stakeholders from a stratified sample of UK construction professionals via a questionnaire-based survey.

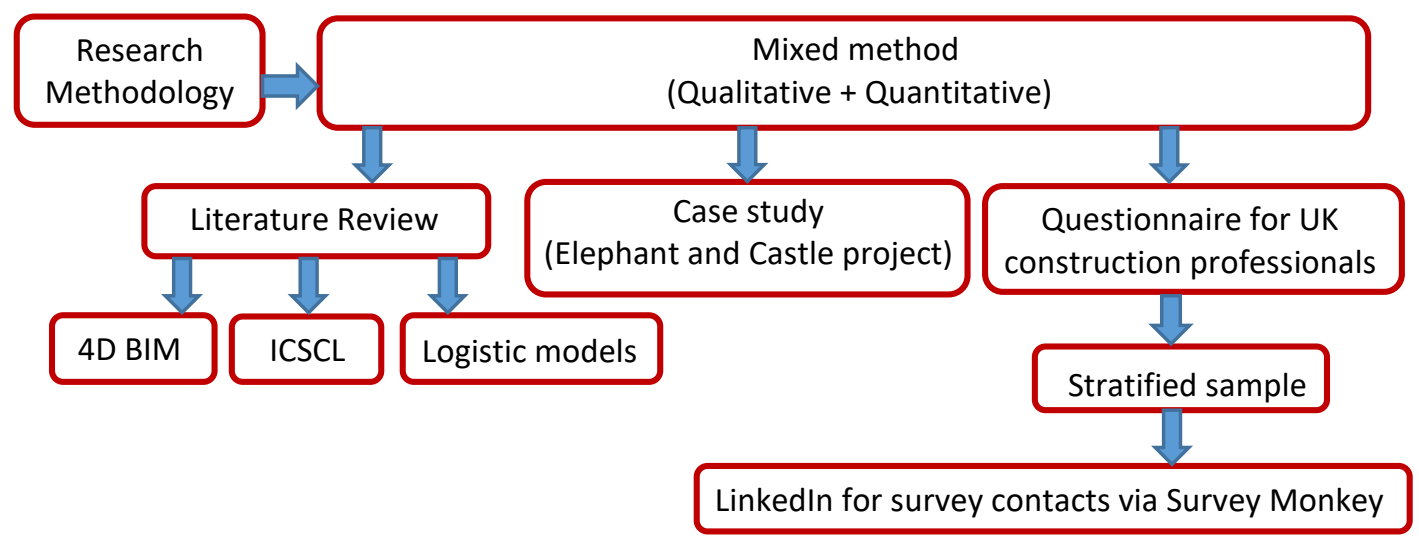

Figure 1. The outline methodology of the research 


\subsection{Literature Review}

The purpose of the review is to identify common trends in the existing research related to $4 \mathrm{D}$ BIM and ICSCL.

\subsection{1. $4 D$ BIM and ICSCL}

BIM is defined as tools, processes and technologies that are facilitated by digital machinereadable documentation about a building, its performance, planning, construction and later its operation [7]. 4D BIM is the addition of time to BIM by linking attributes in the model to a construction programme [8].

Integrated Construction Supply Chain Logistics (ICSCL) is defined as a collaboration between the planning team, supply chain trade contractors and site management in carrying out procurement, pre-construction and the construction activity, including access and egress for logistics movement. Disruptions during construction can cause a loss of productivity of 25 per cent [9]. 4D BIM leads to a visually holistic approach for preconstruction planning, mobilization and completion of the programme activity while interfacing with trade contractors [10]. Hence, it optimizes the laydown zone options for materials and equipment, avoiding clashes and conflicts, thereby eliminating potential production downtime.

4D BIM is not just related to handling and communicating information, but a tool to control project time [11]. If deadlines start to fall behind, 4D BIM enables decision-makers to explore all available resources to make up the difference [12]. However, this innovation is currently not utilised to its best advantage regarding the reduction of overall construction time, which is a requirement of the Construction 2025 vision [5].

\subsubsection{Forces Driving the Practical Use of $4 D$ BIM and ICSCL}

The innovation of BIM drove the industry forward by integrating the process and the team around the product. The ambition was a modern construction industry to increase the efficiency by $3 \mathrm{D}$ object-oriented modelling, as a promising development within the project lifecycle [13]. The current factors that are driving the practical use of 4D BIM and ICSCL are led by the deliverables of Construction 2025 [5], whose vision fundamentally requires greater efficiencies for the construction industry. A key factor from those, is a 50\% reduction in the overall time from inception to completion for new build. Government Construction Strategy (2016) has set out a strategic action plan for the construction industry [18]. BIM Level 3 leading to 4D BIM is seen as the technology of collaboration for project teams of each discipline to lead this transformation of the industry. However, the 2016 report falls short of addressing the actual steps to achieve the goal of BIM Level 3 or add any Government investment streams or funding to raise awareness or train the construction industry disciplines holistically in the use of 4D BIM across project lifecycles.

Standing on $41 \%$ in 2016, project time predictability is still a major issue in the present state of the construction industry in the UK [14]. The intention to improve project time predictability within the construction industry by realising the potential correlation between efficient construction logistics and time predictability, can be a key driver towards using 4D BIM. 


\subsubsection{Barriers for 4D BIM to Release Efficiencies within ICSCL}

Training and awareness issues are amongst the barriers to the use of 4D BIM with ICSCL. Achieving 4D BIM will first require BIM Level 3 to be fully mature; currently, this is not the case in BIM educational terms for construction individuals. The training and awareness of BIM for construction professionals is fragmented, as the majority of BIM training and education is self-sourced by pro-active individuals rather than organizations [15]. The necessity for investment from stakeholders to proactively ensure successful implementation of BIM Level 3 or 4 is in question, particularly while contractors' profits remain low [14]. Insufficient use of 4D BIM within the construction industry can also be attributed to a lack of industry expertise and training for education providers [16]. This trend has continued with low awareness at the project team level. Project team members drive the processes, manage client expectations and contractor milestones. Therefore, they should be trained on innovations that gain time and cost benefits, while this level of staff members are the most time poor of individuals [15]. This project group is the direct interface with the construction supply chain and, as such, plays a major part to move the supply chain forward to integrate 4D BIM.

Strategic forces acting towards adoption of 4D BIM with ICSCL are still lacking. The use of BIM Level 2 by key members of the integrated team has been a Government prerequisite for all its UK projects [8]. Successful delivery of Level 2 BIM objectives identified by the Government Construction Strategy (GCS) was a big achievement towards the digitalisation of the built environment sector [17]. This journey continues, with the next goal being BIM Level 3. Government Construction Strategy (2016) sets out the UK construction strategy as such; "The continued embedding of BIM Level 2 is crucial to support government adoption of BIM Level 3 at a later date'[18]. This 'later date' is not specified or discussed further, nor is there a complete route map disclosed. This leaves the goal-driven industry with no clear direction of the steps or tasks required to be fulfilled to achieve the vision of BIM Level 3 or, indeed, 4D BIM.

\subsubsection{Logistic Models Supporting 4D BIM and ICSCL}

JIT logistic model: Just-in-time (JIT) production means to produce the necessary units in the necessary quantiles at the necessary time [19]. This model is characterized by careful planning, daily management executed from the project site, and immediate and direct feedback of all errors. JIT allows site supervisors to participate in relation to the required logistic movements for the week ahead by making ready the work zones. Without the required workflow of integrated logistics materials, equipment and information, thus workforce production will suffer due to delays [9]. 4D BIM is a tool that generates an intelligent workflow when ICSCL visually collaborates with all stakeholders.

Third party logistic (TPL) model: Construction production activities require their own bespoke model for each specific project. The true concept of JIT deliveries, which make use of spaceconstrained construction sites with a logistics cloud-based delivery booking system, may cause production delays [20]. The London Consolidated Construction Centre (LCCC) managed JIT deliveries for four major centrally based London projects by consolidating the materials in one location and then forwarding on exact material requirements daily to each project site, as they were called off by the site teams [21] (Figure 2). 


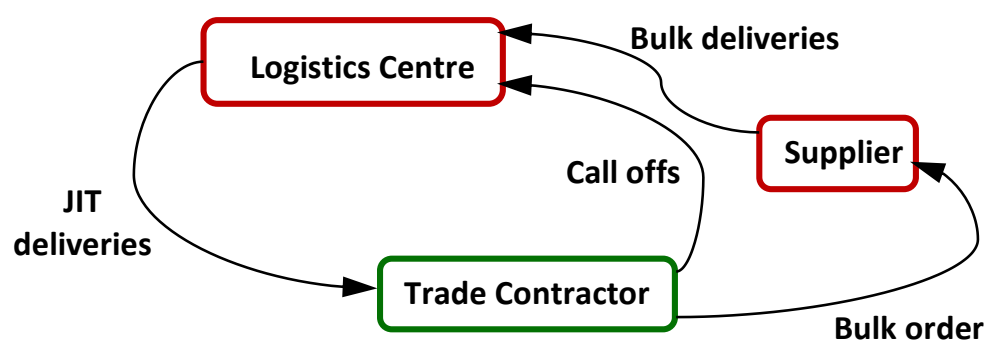

Figure 2. London Consolidated Construction Centre logistics for multiple sites

This TPL model achieved a 97\% reliability of JIT deliveries and reduced journey times significantly. The model also involved the collaboration of contractors and suppliers to actively engage in time and waste reduction by using smart logistics to track all deliveries. An additional benefit was that reverse logistics (waste stream removal) was managed by the transport carrying out the JIT deliveries. However, this model comes at a financial premium. The TPL provider service attracts a cost which can be allocated transparently and fairly to the subcontractors. This cost erodes profit and, therefore, impacts on the reinvestment of new technologies. The LCCC model related to JIT by a TPL provider facilitates construction works on multiple sites. This model can be modified to suit one site by utilising a TPL provider without the consolidation Centre [22].

On-site Production model: This model uses BIM-based solutions, web based software for procurement and tagging of materials. Although this model offers safety stocks for materials aiding the supply chains resilience, it requires on-site double handling of materials and equipment. Prefabrication of construction components is an additional project cost, although time can be saved using prefabrication and quality is improved by factory manufacturing. This greater time certainty and quality assurance can mitigate the additional associated extra costs. Therefore, prefabrication can add value, the main value to the client being time predictability. Point-of-use deliveries tend to be pre-planned to a greater degree by project staff due to the cost impact of delayed transport and the installation team's potential downtime. Transport for point-of-use materials and equipment requires the ability to control the exact timings of transport to be coordinated with vertical and horizontal off-loading zones [23].

Each of the reviewed logistic models have advantages and disadvantages, depending on the competency of project staff and the complexity/constraints of the project. However, none fully addresses the production issues that may stop or delay an activity [9], which is further evidenced by the $41 \%$ UK project time certainty [14].

Space must be considered in 4D BIM as a resource [24]; quantified sequenced space must be linked to time within each activity in the visual programme. Access and egress must also be considered as a primary resource to allow workflow. These last two attributes are not identified specifically in the literature reviewed. Equally important are reverse logistics for reducing, recycling, reusing/recovering and managing the disposal of waste materials streams, including packaging [25].

\subsection{Case Study}

This case study describes the use of ICSCL integrated with 4D BIM in real time, by capturing the overall strategy and the daily interactions of construction logistic planning. The strategy of this project is explored regarding time predictability, training and awareness, drivers and 
barriers of sharing information, planning integration, IT infrastructure, the motivation of stakeholders, logistic model and financial constraints of 4D BIM and ICSCL.

The Elephant and Castle $(\mathrm{E} \& \mathrm{C})$ is a $£ 2$ billion redevelopment programme over 11.4 hectares of land located in the area known as Elephant and Castle in the London Borough of Southwark in the UK. This specific phased project is ongoing until 2025 after the construction phase begun in 2012. The master plan includes over 2000 new homes, parks, cycle networks and retail development. This project is one of the 18 chosen worldwide to be a part of the Climate Positive Development Programme.

This project is selected for the case study, as it utilises 4D BIM since 2015, for construction phase planning collaboratively integrated within the supply chain to manage construction logistics, thereby achieving some maturity. The construction management organisation, Lend Lease, has a history of supply chain management and knowledge sharing within its own work streams.

With respect to the large size of the project, the E\&C case study was not exhaustive, due partly to this project being scheduled to be delivered in 2025 and due to the nature of projects which is made up of phases of work. Therefore, the current phase of the project, West Grove Major Phase 2, was the subject of this case study. West Grove Major Phase 2 contains plot H2 and H3, with the focus of the case study being on plot H3 (See Figure 3). Plot H3 comprises four buildings above a common podium, which includes one tower of 19 storeys.

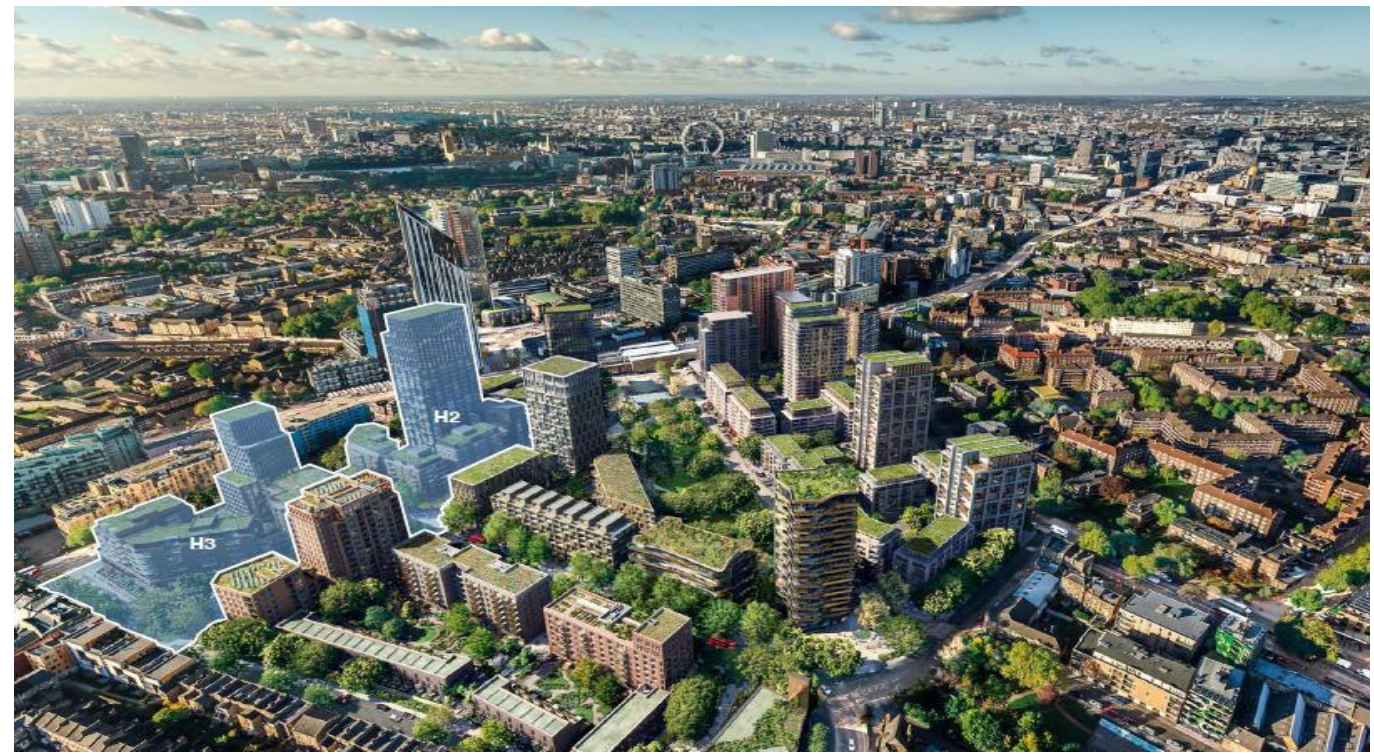

Figure 3. $\mathrm{H} 2$ and $\mathrm{H} 3$ proximity within the $\mathrm{E} \& \mathrm{C}$ Regeneration project [6]

The construction management model involves early engagement of the supply chain contractors procured in work packages of design and construction disciplines, whereby the employer, in this case, the main contractor appoints separate trade contracts to deliver the project coordinated by a construction management organisation. This organisation is another Lend Lease division, which manages both the pre-construction and project delivery. The construction management model has advantages for the company, which has a history of knowledge sharing within its own work streams, prequalifying its supply chain contractors and its positive management [6]. 
To coordinate multiple construction trades on this project, given the close proximity of the towers to existing residential and mixed use live zones, management of the supply chain logistics is critical. Any loss of production by the contractors due to logistical issues for men, materials, equipment and information is determined by the Main Contractor. This risk drove the need for time certainty by using a visual plan and is, therefore, mitigated by the use of 4D BIM integrated within the supply chain to pre-plan the works with the trade contractors.

The project practises a hybrid of the logistic models discussed in Section 2.1. A TPL provider is employed. Next, the LCCC model is operated for specific construction items. Finally, an offsite staging zone is utilised to facilitate JIT for point-of-use materials (see Section 2.1.4). This enables the delivery streams to be managed with flexibility to enable the best TPL service for all stakeholders while minimising the construction impact on the local community and road networks. The ambition is to allow the 4D BIM to facilitate procurement, although this has not yet been realised.

The site teams plan logistics by approaching the activity on two fronts. The three-month programme is taken from the remaining project duration of circa nine years. This is planned by the Senior Planning Manager, Project Director and Construction Manager and then visualised by the Senior BIM Manager. At the workface, the site supervisors and the Main Contractor construction managers meet daily to communicate the allocation of resources, prioritise work zones and discuss logistics, thus coordinating the works with all stakeholders. These on-site coordination meetings are convened using visual aids (whiteboards, noticeboards and handheld devices). This meeting also includes the dispensing of work permits and permit records which are located at the end of protected walkways within the building under construction. The trade supervisors also brief their workforce with the same visual materials at the same on-site location. The site teams use hand-held tablets to view the 4D BIM and manage the project management platform, which contains, but is not limited to, contract drawings, programmes, inspection requests, ITPs, method statements, testing and commissioning records, punch lists and specifications. A daily meeting is also held with all trade supervisors to ensure that the prerequisites for any upcoming activity are carried out to allow the flow of materials, plant and equipment, information, workforce and space. The system works to the method proposed by Mossman [26], the Last Planner System, although, in essence, the organisation was using this construction management procedure before 2007. The daily meeting allows the Main Contractor Construction Managers to complete a three-week look ahead programme, which also develops ownership to deliver. The additional visualisation of these works allows all stakeholders to analyse the best options in real time and make appropriate corrections in collaboration with the construction managers and other trade contractors. The agreed activity information is passed down to the trade gang leaders and workforce so that all parties are aligned.

Part of data regarding the initiatives used on this project was collected via structured interviews of key project stakeholders. The interviews allowed qualitative data to be extracted by the use of open and closed questions to allow views to be expressed within an overall framework of questions. Figure 4 shows the E\&C strategic project staff hierarchy, which support the project site supervision. As shown in this figure, some project staff are responsible for one phase dayto day planning and implementation of the works. These staff members were asked questions on the drivers and barriers of 4D BIM with ICSCL with regard to the methods employed, the results achieved and subsequent lessons learnt. Some project staff are responsible for the overall scheme of the project. These positions are able to set the policies and make decisions of how the project is delivered; therefore, they were also asked questions on the project's 
strategy. In total seven key staff positions were interviewed from this project. The list of questions asked in the interviews and a summary of responses are given in Section 3.

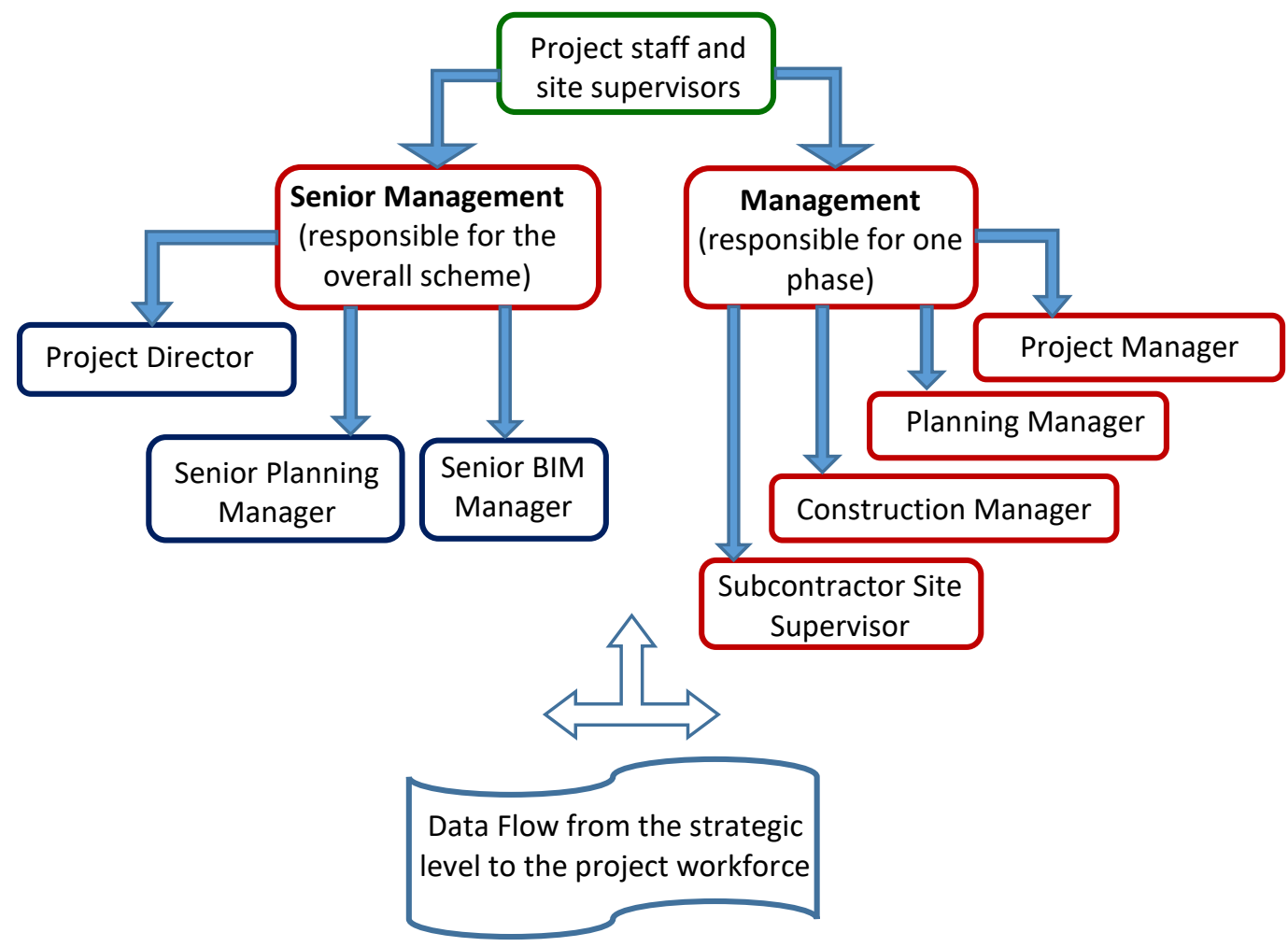

Figure 4. Project staff data capture model

\subsection{Questionnaire-Based Survey}

The views of construction professionals ascertained, gave up-to-date perspectives which added depth to this study. The questionnaire for the stratified sample of $60 \mathrm{UK}$ construction professionals with vast and varied experience within the industry was sent out using Survey Monkey via social media (Linkedin) to the same disciplines as the E\&C case study project staff. The 60 samples were selected based on the cross-sectional nature of this study and access to construction stakeholders. The questionnaire was validated using an initial pilot study to ascertain the suitability, reliability and timeliness of the questions posed in the research instruments. The initial pilot study was conducted through the validation of the responses by 5 selected construction professionals. The outcome of the validation was used to enhance the questions before distribution.

The expected response rate was 50\%, which allowed the data from 30 anticipated responses to be used. All respondents remain anonymous: names were not requested within the questionnaires, only the respondents' positions within their organisations were disclosed to enable the data to be analysed. This data is summarised in Section 3 and the results are compared and contrasted to the case study findings and literature review in grouped themes.

\section{Research Findings, Results and Discussion}

Figure 5 summarises the process of data collection and analysis. 


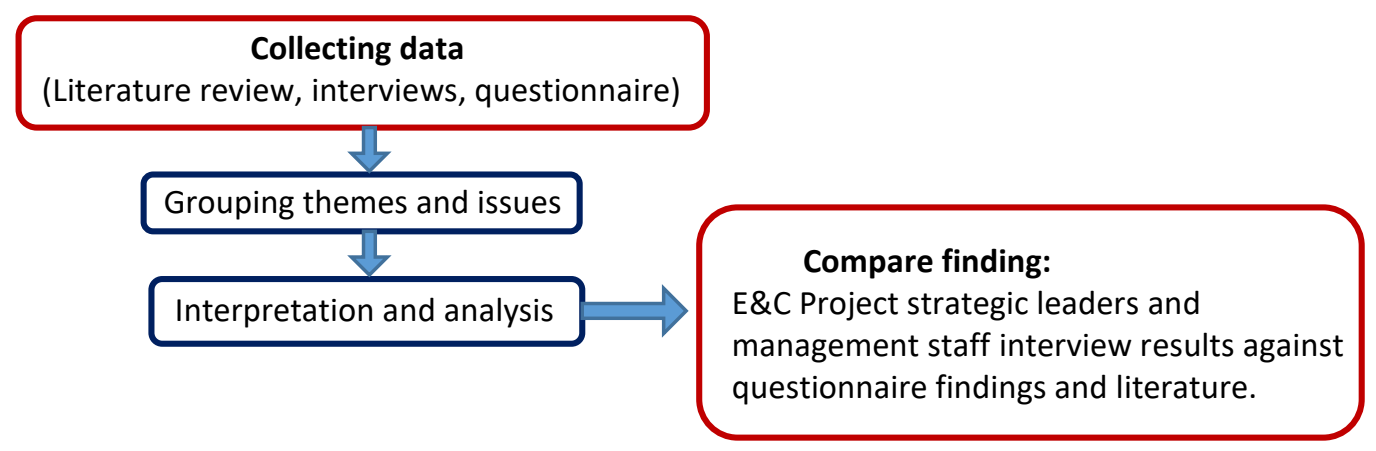

Figure 5. Process of data collection and analysis

The case study interviews and the questionnaire for the survey were constructed in emerging themes. As stated in Section 2.2, in the interviews of E\&C project there were separate questions on strategy for senior management. Table 1 shows the themes of questions with question number breakdown for Senior Management and Management levels.

Table 1. Themes and number of questions for the interviews and survey

\begin{tabular}{ccc}
\hline Themes and number of questions at each level & Senior Management & Management \\
\hline General factual & 4 & 4 \\
Project strategy & 5 & 0 \\
4D BIM training and awareness & 5 & 5 \\
Planning integration with the supply chain & 5 & 5 \\
IT infrastructure & 2 & 2 \\
Motivation of stakeholders & 2 & 2 \\
Logistic model & 5 & 5 \\
Financial constraints & 2 & 2 \\
Reflective & 2 & 2 \\
\hline
\end{tabular}

The same questions formed the questionnaire for the survey, to enable an in depth understanding of various projects of different values across the UK, adding validity and further reliability to the study. The emerging difference between the two data streams was that the questionnaires contained options for ticking some of the pre-described responses, with the further option of another descriptive box in order to capture open non-leading responses.

The findings of this research are discussed in grouped themes. Questions and a summary of responses for both the case study interviews and the questionnaire-based survey are given in each section.

\subsection{Theme of Analysis: Project Strategy}

Table 2 gives the questions under this theme and a summary of responses from the case study interviews.

Table 2. 'Project Strategy' questions and summary of responses from the case study

The principal driver to utilise 4D BIM for visual construction planning?

- Pre-construction program $\bullet$ Clash detection $\bullet$ Buildability $\bullet$ Logistics modelling

The major barrier to integrate 4D BIM into the construction supply chain?

- Lack of education and awareness of 4D BIM within the trade contractor's workforce

- Supply chain capability

- Lack of case studies and the uncertainty over legal implications regarding contractual 4D BIM

- Contractual issues bringing a sense of unease to the trade contractors 
The major driver of the project strategy regarding logistics?

- Activity time reduction $\bullet$ Quality enhancement $\bullet$ Pre-construction program buildability

How the logistics project strategy using 4D BIM could increase site production levels?

- By conducting a construction rehearsal to sequence the works

- By conducting a construction rehearsal to plan the works which adds to safety and quality

while gaining clients' trust

- By simulating temporary works

How project strategy of 4D BIM and logistics can be measured to evidence benefits?

- Production increase of the site activities $•$ KPIs to monitor and review project time certainty

Interview outcome shows that the E\&C project has embraced 4D BIM and ICSCL and has experienced greater time predictability as a result. In this case study, logistic modelling, clash detection and buildability were the drivers of using 4D BIM. The survey results reveal that, although the majority of respondents (76\%) use BIM at various levels (36\% BIM Level 2, 26\% BIM Level 3, and 14\% BIM Level 4), in general no cohesive strategy is in place to manage the use of 4D BIM with ICSCL in the UK construction industry.

In the $\mathrm{E} \& \mathrm{C}$ project, major barriers to integrate 4D BIM into the construction supply chain are lack of education and awareness of 4D BIM within the trade contractor's workforce, lack of case studies and the uncertainty over legal implications regarding contractual 4D BIM. The survey results clearly identified that lack of training and awareness (43\%), and technical issues with the models and IT systems $(43 \%)$ were the major barriers, which were also revealed from the literature review. Lack of interest in clients or unclear recognition across the supply chain can be another barrier as claimed by $14 \%$ of the respondents.

In the $\mathrm{E} \& \mathrm{C}$ project, the major drivers of the project strategy regarding logistics are activity time reduction, quality enhancement, and pre-construction program buildability. For the surveyed projects, the major drivers are activity time reduction (32\%) and cost benefits (24\%), while safety, site constraints, quality enhancement, and waste reduction are the minor drivers of the project strategy $(6 \%-12 \%)$.

In the E\&C project, the logistics project strategy using 4D BIM increases the site production levels by conducting a construction rehearsal to plan and sequence the works, which adds to safety and quality, and by simulating temporary works in the visual planning. The survey responses also indicate that logistics project strategy using 4D BIM could increase production levels by producing a construction rehearsal (44\%), by enabling production clashes to be identified (26\%), and by enabling procurement of materials to be delivered just in time (15\%). This can reduce activity time, bringing with it safety benefits by mitigating risk (the drivers identified above).

In response to measurement of 4D BIM and logistics to evidence benefits, the measurement of production for all site activities is considered as fundamental by E\&C Project strategic leaders and management staff. This was confirmed in the survey by $50 \%$ of respondents stating the importance of KPIs. Use of KPI trends is further identified in the literature, as a way of measuring the benefits of $4 \mathrm{D} \mathrm{BIM}$ and ICSCL in order to raise awareness within the industry and to educate the market via published case studies [14].

\subsection{Theme of Analysis: Training and Awareness}

Regarding the major barriers of using 4D BIM within the UK construction industry, both the case study and the survey raised the issue of lack of training and awareness as the major barrier 
to integrate 4D BIM into the construction supply chain, such as, within the trade contractor's workforce. This was also clearly revealed from the literature. Table 3 summarizes the responses obtained from the case study interviews for the questions under this theme.

Table 3. 'Training and Awareness' questions and summary of responses from the case study

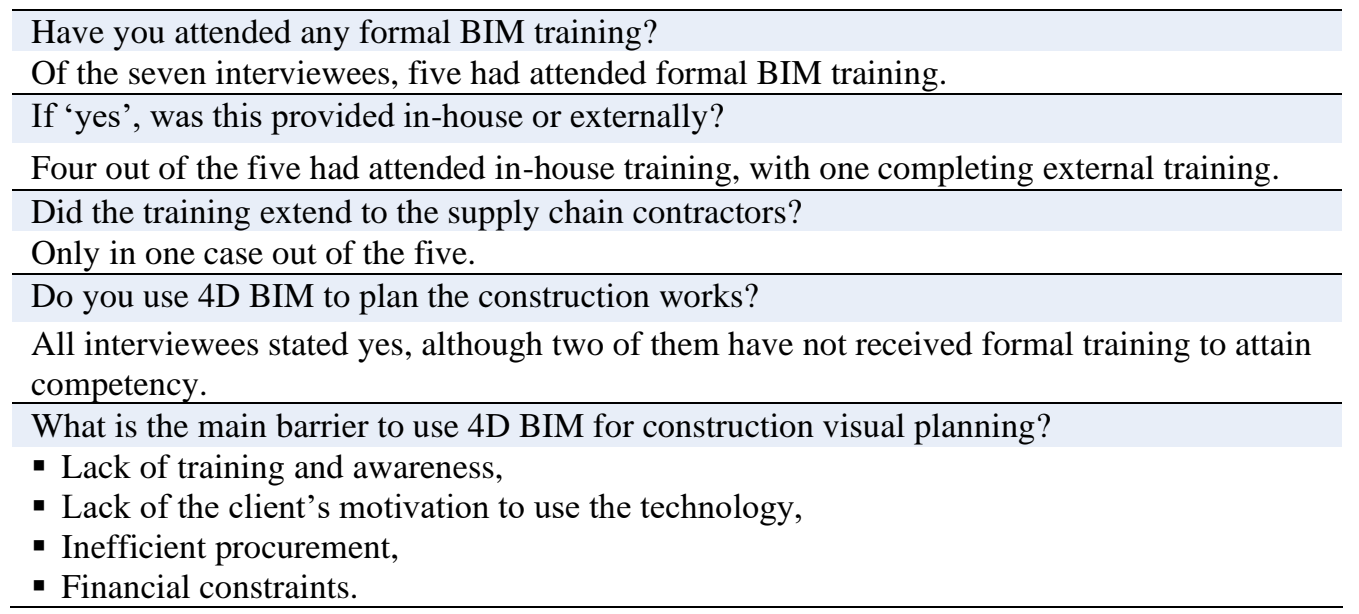

As shown in this table, the majority of interviewees from the $\mathrm{E} \& \mathrm{C}$ project have attended formal BIM training, while only $45 \%$ of the survey respondents have done the same. The survey result highlights the current status of the UK construction industry, where more than half of the construction professionals have not received formal BIM training.

Of those who have attended BIM training, in both case study and survey, the majority have been provided via in-house courses and the training has been rarely extended to the supply chain contractors. The in-house quality of training may be called into question as it might be completed in a matter of days with no recognised qualification to ensure knowledge-based competency.

In the E\&C case study project, all of the interviewees use 4D BIM to plan the construction works, although some of them have not received formal BIM training. Of the survey respondents, only $24 \%$ of them use 4D BIM to plan the construction works, and the majority of them do not use it as a consequence of lack of awareness and low motivation of the clients and stakeholders.

\subsection{Theme of Analysis: Planning Integration}

Table 4 summarizes the responses obtained from the case study interviews for the questions under this theme. In the E\&C project, planning happens in weekly meetings with all stakeholders. The planning process is taken from a long range baseline programme plan, which is visualised over 3-5 years at a high level then split into year quarters. It is then given higher levels of detail captured on a three-month Gantt chart and then visualised to effectively plan logistics using both 2D CAD drawings and 4D BIM. The software used for planning is Primavera P6 [27]. Visualisation is carried out by the 4D Scheduling \& VDC Project Management Platform authored by Synchro [28]. The visual planning is communicated to the workforce supervisors in specific weekly meetings. In this project, the lessons learnt from logistic planning are captured and communicated to project stakeholders by being uploaded onto the company web-based share portal. The knowledge gained is also incorporated into the organisations' policies and procedures on regular basis. 
Table 4. 'Planning Integration' questions and summary of responses from the case study

The brief project plan regarding supply chain logistics?

Weekly planning meeting with all stakeholders, stated by all interviewees.

How long is the visual (or Gantt chart) planning process for logistics carried out in advance for integration into the project programme?

The planning process is taken from a long range baseline programme plan, which is visualised over 3-5 years at a high level then split into year quarters.

How the visual planning is communicated to the workforce supervisors? Please specify whether it is 4D BIM visual planning or Gantt chart.

Specific weekly meetings, to disseminate planning information directly to the stakeholders. The year quarter or the three-month plan on a Gantt chart and then visualised using both 2D CAD drawings and 4D BIM.

Is space to work or lay down materials considered as a planning resource?

All interviewees confirmed 'yes'.

How the lessons learnt from the project regarding logistic planning are captured and communicated?

A combination of Communities of Practice, company web-based share portal and information shared to all stakeholders gave a rounded response to Lessons Learnt capture of information.

The survey results indicate varied approaches to planning and its communication, with some aspects lacking the disciplined approach that must be driven by company policy, procedure and audit, which the E\&C project benefits from. In the majority of the projects (59\%), the visual planning is communicated to the workforce supervisors in specific weekly meetings. Only a minority of respondents $(12 \%)$ use Communities of Practice to capture and communicate project information. Therefore, the knowledge output may not be incorporated into the organisations' procedures, and the Lessons Learnt from past experience can become lost. Space is used as a planning resource by $94 \%$ of respondents.

\subsection{Theme of Analysis: IT Infrastructure}

In the E\&C project, all the interviewees confirmed that the IT infrastructure is in place with on-site handhelds to upload and download information via the project management platform. This is an important investment in IT and the associated training.

The survey results show that the IT infrastructure to manage BIM is in place in the majority of projects (79\%). However, the availability of handheld devices is very limited (only in $35 \%$ of the surveyed projects), showing that 4D BIM can be office based in the current conditions. It was also evidenced that the supply chain does not have the capability to use 4D BIM, where investment is required at all levels.

\subsection{Theme of Analysis: Motivation of stakeholders}

As the case study and the survey results indicate, most of respondents ( 4 out of 7 interviewees from the E\&C project, and $82 \%$ of the surveyed professionals) believe that the contractors are not capable to collaborate in the use of 4D BIM for planning site logistics, mainly as a result of inadequate awareness.

The survey results reveal that the clients are mostly not motivated (in $74 \%$ of the projects) towards the use of integrated 4D BIM for supply chain logistics. However, in the E\&C project, the client is motivated to use this technology (claimed by all of the interviewees), as the joint client and the management contractor have the same vision (see Section 2.2). There may be some other causes for such motivation in the $\mathrm{E} \& \mathrm{C}$ project, including the maturity of the project 
in terms of the capacity of the supply chain to effectively collaborate with 4D BIM and ICSCL, as well as the availability of advanced IT Infrastructure.

\subsection{Theme of Analysis: Logistic Models}

In the E\&C project a TPL is engaged, as revealed by the interviewees, for movement of materials and equipment (see Section 2.1.4). JIT deliveries and the consolidation centre enable flexibility and control using a logistic software tool. The overall project site logistics are specifically funded by the client and the logistics plan is communicated weekly to the stakeholders by visual materials. Time, cost and quality are all influenced by logistics [29]. As a result, a clear logistics planning scope is employed with stakeholders' commitment and understanding.

Within the majority of the surveyed projects $(56 \%)$, each contractor manages their own logistics. A low number of the projects use a TPL provider (12\%), a staging area to facilitate JIT deliveries or a consolidation centre $(12 \%)$, or a consolidation centre for material/equipment to be forwarded on request just in time (14\%). In general, there is a fragmented approach to ICSCL; different projects use different models, none combine the three models discussed in Section 2.1.4 which are utilised by the E\&C project resulting in project benefits. This indicates a missed opportunity to manage ICSCL and integrate 4D BIM planning to mitigate the risks on project time certainty within the UK, which was only $41 \%$ in 2016 , according to Individual KPI Trends [14].

Only in $26 \%$ of the surveyed projects, the overall project site logistics is specifically funded by the client, as is the case for the $\mathrm{E} \& \mathrm{C}$ project. The majority of the projects use visual materials and site plans (79\%), but not 4D BIM, which can alleviate long-term interface of trade contractors' materials and equipment clashes, resulting in ineffective downtime.

Although this study did not investigate prefabrication in detail, it is noted that using prefabricated construction components, the time saved and quality benefits come at a premium cost. The E\&C project utilises many prefabricated construction components. The use of prefabricated components was also reported in the majority of the surveyed projects $(77 \%)$, which is encouraging for the industry.

\subsection{Theme of Analysis: Financial Constraints}

Table 5 summarizes the responses obtained from the case study interviews for the questions under this theme.

Table 5. Questions regarding 'Financial Constraints' and responses from the case study

Do you believe that training for BIM is restricted due to the industry's current low profitability?

Three interviewees responded positively and four of them responded negatively.

Are the project site logistics given the funding required to allow materials, equipment and waste

to be proactively managed with ongoing site activities within their planned timescale?

Six interviewees responded positively and one of them responded negatively. 
Investment is required to fund 4D BIM formal training, software and IT infrastructure to ensure that collaboration takes place at all levels, the E\&C project being an example. The survey results clearly indicate that low-profit margins affects training (as confirmed by $62 \%$ of the respondents), and lack of logistic funding (which is the case for $39 \%$ of the surveyed projects) affects production time certainty. The model to fund logistics via a TPL should be seen as best practice. This would enable trade contractors to concentrate on carrying out the works to the required quality, safely and within the time constraints without the need to further consider how to streamline material and equipment movements. Moreover, the TPL provider deals with reverse logistics, which removes waste streams efficiently by reusing and recycling.

\subsection{Reflective Questions}

All the respondents from $\mathrm{E} \& \mathrm{C}$ project believe that 4D BIM did produce logistic efficiencies. Majority of them state the added value to the project outweighs the initial costs (Table 6).

Table 6. Reflective questions and responses from the case study interviews

\begin{tabular}{l} 
Do you believe that 4D BIM can produce logistic construction efficiencies? Please give brief \\
details. \\
The responses from all interviewees agree that 4D BIM did produce logistic efficiencies. \\
What is your opinion of the extra costs involved for 4D BIM planning verses the perceived \\
benefit of time certainty for project delivery? \\
Six interviewees confirmed that 4D BIM added value to the project outweighing the initial costs. \\
\hline
\end{tabular}

From the survey results, $76 \%$ of the respondents believe that 4D BIM can produce logistic construction efficiencies. Visualising the works and reviewing the risks in a visual format provides considerable benefits to the site team. Clash detection alone, as one benefit of using 4D BIM, improves the quality of the design reducing potential waste on the scheme. This allows the buildability to be reviewed in advance and logistical methods analysed to improve programme. However, training and awareness is an inadequacy which needs to be addressed if the industry is to move forward with a structured programme to award formal accreditation relevant to the needs highlighted for 4D BIM visual planning. Planning, as a key function, requires competent resources. Training has always been a major challenge in implementing BIM [30]. Monitoring and review stages are project management controls; however, if the site supervisors help to develop the three-week look ahead and commit to this, then ownership is developed by the trade contractors. Stakeholder and Client engagement is key; In the E\&C project all stakeholders are actively engaged in the visual planning process and reaping the reward of time certainty.

Regarding the cost/benefits involved, 35\% of the respondents stated that 4D BIM and ICSCL would be beneficial for projects, however, $25 \%$ of them had no knowledge or little experience in the cost aspect. A lower number of respondents perceived that the costs of IT infrastructure are high and not included in the budgets, particularly in small turnover organisations. Modular coordination is essential for successful utilisation of 4D BIM [31]. Hence, a 3D reference system can be used for sizing and placing building elements before 4D visualisation. However, time certainty is worthy of investment and this investment would bring benefits; "The cost could not be more than the costs of lay down and workforce clashes causing downtime". The difficulty, however, is convincing the clients to think about the future cost savings instead of the initial cost. Nevertheless, clients must not be used as a reason to instigate the use of 4D BIM and ICSCL. The supply chain system must be integrated with BIM to alleviate the burden of information management among the stakeholders [32]. It is the main contractors and their 
trade contractors that must transform their current practices to increase production and reduce waste to ultimately increase their market share and profits.

\section{Implications of findings for further studies}

For an effective integration of 4D BIM ICSCL, the enablers supporting 4D BIM and ICSCL begins with government policies and investment as a motivation for the construction industry's readiness for $4 \mathrm{D}$ BIM. In figure 6 , there is a representation of all the drivers and barriers identified, through literature and primary data collection. The findings in figure 6 are all part of a system required for a successful integration of 4D BIM and ICSCL.

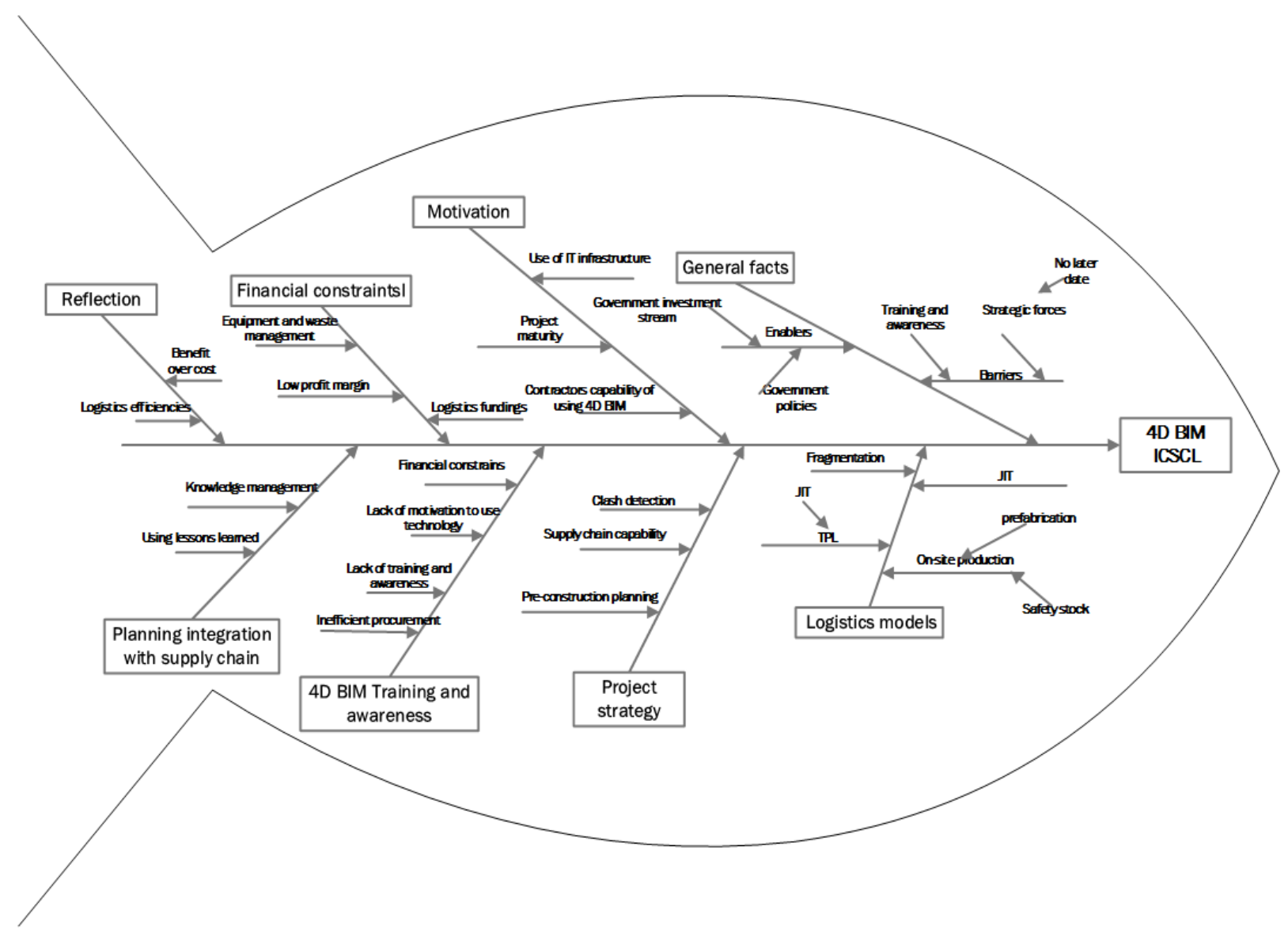

Figure 6. Fishbone diagram representing the drivers and enablers for a 4D BIM ICSCL

A congruent resolution of the barriers associated with the fishbone diagram in figure 6 potentially creates an opportunity not just for 4D BIM with ICSCL but also 5D BIM. The reflection theme identified benefit over cost when 4D BIM is integrated with ICSCL. Further studies into where cost in 5D BIM has been implemented with ICSCL will further mitigate the aforementioned variables.

\section{Conclusions}

In this paper, the use of ICSCL integrated with 4D BIM in the UK construction industry was investigated, via three information streams: literature, a case study of the E\&C project, and a survey from a stratified sample of UK construction professionals. 
The results show that there is no cohesive strategy in place to manage the use of 4D BIM with ICSCL in the UK construction industry. Although the concept of 4D BIM is known and activity time reduction is a major driver for use of $4 \mathrm{D}$ BIM with ICSCL, the main barriers are IT infrastructure and training. It appears that weak construction profit margins are affecting future investment in people and IT, which, in turn, reduces project time certainty. The study evidenced a lack of discipline to plan and manage the trade contractors across the UK construction industry, amounting to a missed opportunity in terms of collaboration.

The findings of this research leads to the following recommendations for the industry:

- The 4D BIM to be incorporated in the project strategy with trusted supply chain contractors engaged early on to add to the construction rehearsal before allocating physical resources.

- Formal training and awareness of 4D BIM and ICSCL to be a priority pursued by visionary leadership focused on this transformational change, embedded by organisation values and beliefs.

- Advanced planning integration using 4D BIM is essential for time certainty, in which space is a resource and access and egress constraints are critical to avoid double handling and multiple trade interface clashes.

- The IT infrastructure to manage the BIM combined with the project management platform is required to facilitate the use of 4D BIM and ICSCL. Contractors must drive this change by drilling down through the levels of their supply chain, in collaboration with project stakeholders potentially using handheld devices at site level.

- The logistic model to investigate the use of a TPL to facilitate the works with a transparent cost model as the starting point and then move forward with planned staging points for JIT, laydown allocation and the horizontal and vertical corridor transport plan. A disciplined approach to be in place to communicate, monitor and review this plan by a visual dashboard.

- The financial constraints to be addressed at the strategic management level. Contracts to include financial mechanisms to share the transparent cost of logistic collaboration.

This research is limited to the UK construction industry, and globalisation of the research findings may be biased without verifying the result by undertaking more case studies across the world. Further research is recommended to establish robust case studies that evidence KPI benefits regarding safety, quality and cost relative to time certainty for 4D BIM and ICSCL.

\section{REFERENCES}

[1] Gilory E. (2016), Tackling waste management in construction, Recycling and Waste world, http://www.recyclingwasteworld.co.uk/opinion/tackling-waste-management-in-construction/114342/

[2] BMN (2017), How can we solve the construction industry's waste problem,

http://www.buildersmerchantsnews.co.uk/news/fullstory.php/aid/14717/How_can_we_solve_the_construction_industry_92s _waste_problem_.html

[3] National BIM Report (2018), Royal Institute of British Architects, RIBA Enterprises Ltd.

[4] Building Information Modelling (2012), Industrial strategy: government and industry in partnership, HM Government, London.

[5] Construction 2025 (2013), Industrial strategy: government and industry in partnership, HM Government, London.

[6] Elephant \& Castle Regeneration (2014), West Grove Final Designs and Exhibition, Lend Lease,

http://www.elephantandcastle-lendlease.com

[7] Eastman C., Teicholz P., Sacks R., Liston K. (2011), BIM Handbook: A Guide to Building Information Modelling for Owners, Managers, Designers, Engineers and Contractors, $2^{\text {nd }}$ ed., John Wiley \& Sons.

[8] Sinclair D. (2012), BIM Overlay to the RIBA Outline Plan of Work, RIBA Publishing, London.

[9] Bryer L., Hastings J., Forbes D., Horner M. (2016), Construction Labour productivity: identifying the causes of trends, BSRIA, https://www.bsria.co.uk/news/article/construction-labour-productivity-identifying-the-causes-of-trends/ 
[10] Bortolini R., Shigaki J.S. and Formoso C. T. (2015), Site logistics planning and control using 4D modelling: a study in a lean car factory building site, Proceedings of the 23rd Annual Conference of the International Group for [11] Gledson B. and Greenwood D. (2016), Surveying the Extent and Use of 4D BIM in the UK, Journal of Information Technology in Construction, 57-71.

[12] Oracle (2013), Meeting the Challenges of Infrastructure Growth by leveraging 4D Building Information Modelling (BIM), California, USA.

[13] Eagan S. J. (1998), Rethinking construction: the report of the construction task force, Department of the Environment, Transport and the Regions, London.

[14] Constructing Excellence (2016), UK Industry Performance Report, HM Government, London.

[15] Gledson B., Hilton D., Rogage K. (2016), Benchmarking BIM Levels of Training and Education amongst Construction Management Practitioners, Proceedings of the 32nd Annual ARCOM Conference, Manchester: Association of Researchers in Construction Management, 353-362.

[16] Eadie R., Browne M., Odeyinka H., McKeown C., McNiff S. (2013), BIM implementation throughout the UK construction project lifecycle: An analysis, Automation in Construction, 36, 145-151.

Lean Construction, Perth, Australia, 361-370.

[17] BSI (2016), Specification for information management for the capital/delivery phase of construction project using building information modelling, British Standard Institute, PAS 1192-2, London.

[18] Government Construction Strategy (2016), Infrastructure and Projects Authority, HM Government, London.

[19] Monden Y. (2012), Toyota Production System: An Integrated Approach to Just-In-Time, 4th ed., Institute of Industrial Engineers, CRC Press, USA.

[20] Sacks R., Koskela L., Dave B. A., Owen R. (2010), Interaction of Lean and Building Information Modelling in Construction. Journal of Construction Engineering and Management, 136(9), 968-980.

[21] Transport for London (2008), London Construction Consolidation Centre Final Report.

[22] Ekeskar A. and Rudberg M. (2016), Third-party logistics in construction: the case of a large hospital project, Construction Management and Economics, 34(3), 174-191.

[23] Seppanen O. and Peltokorpi A. (2016), A New Model for Construction Material Logistics: From Local Optimization of Logistics Towards Global Optimization of On-Site Production System, Proceedings of the 24th Annual Conference of the International Group for Lean Construction, Boston, International Group for Lean Construction, 73-82.

[24] Perez C.T., Fernandes L .L. A., Costa D. B. (2016), A literature review on 4D BIM for logistics operations and workspace management, Proceedings of the $24^{\text {th }}$ Annual Conference of the International Group for Lean Construction, 53-62, Boston.

[25] Chinda T. and Ammarapala V. (2016), Decision-making on reverse logistics in the construction industry, Songklanakarin Journal of Science and Technology 38(1), 7-14.

[26] Mossman A. (2007), Lean logistics: Helping to Create Value by Bringing People, Information, Plant, Equipment and Materials Together at the Workface, Proceedings of the 15th Annual Conference of the International Group for Lean Construction, Michigan, 198-211.

[27] Oracle (2017), Primavera P6 Professional Project Management, California, USA.

[28] Synchro (2017), 4D Scheduling \& VDC Project Management Platform, Birmingham, UK.

[29] Khanzadi, M., Sheikhkhoshkar, M., \& Banihashemi, S. (2018), BIM applications toward key performance indicators of construction projects in Iran. International Journal of Construction Management.

[30] Mostafa, S., Kim, K. P., Tam, V. W. Y., \& Rahnamayiezekavat, P. (2018), Exploring the status, benefits, barriers and opportunities of using BIM for advancing prefabrication practice. International Journal of Construction Management.

[31] Singh, M. M., Sawhney, A., \& Borrmann, A. (2019), Integrating rules of modular coordination to improve model authoring in BIM. International Journal of Construction Management, 19(1), 15-31.

[32] Le, P. L., Elmughrabi, W., Dao, T. M., \& Chaabane, A. (2018), Present focuses and future directions of decision-making in construction supply chain management: a systematic review. International Journal of Construction Management. 